\title{
FENOMENOLOGÍA DEL EJERCICIO DE LA LIBERTAD UNA PROPUESTA DESDE LA LOGOTERAPIA Y EL ANÁLISIS EXISTENCIAL
}

\author{
Phenomenology of the exercise of freedom \\ A proposal from logotherapy and existential analysis
}

\author{
Alejandro Khaled Salomón Paredes* \\ Universidad Femenina del Sagrado Corazón - Lima, Perú \\ https://orcid.org/0000-0002-5147-1270
}

\begin{abstract}
Resumen
En este artículo se realiza una investigación descriptiva en primera persona del fenómeno libertad, desde una orientación logoterapéutica fenomenológica, poniendo énfasis en la experiencia de autocomprensión respecto a lo que constituye lo específicamente humano y abre al ser a la existencia: la capacidad de elegir y la responsabilidad frente a sí mismo y sus circunstancias. La ausencia de esta comprensión propia deja a la persona a merced de la naturaleza, los aprendizajes, la sociedad y el destino. La tarea existencial consiste entonces en lograr ese conocimiento propio y asumir el protagonismo en la propia vida. Existir implica no solo ser libre, sino atreverse a ejercer la libertad, reconociendo en medio de la insatisfacción y la angustia la condición humana de estar confrontado con todo, principio fundamental del ser libre. Para este propósito se ha recurrido a autores como Viktor E. Frankl, Max Scheler, Martin Heidegger, Karl, Jaspers, Sören Kierkegaard, Rudolf Allers, entre otros.
\end{abstract}

Palabras Clave: Libertad, responsabilidad, persona, autocomprensión, existencia, condicionamientos, logoterapia, fenomenología, valores, Viktor Frankl.

\begin{abstract}
In this article, a descriptive investigation of the phenomenon of freedom is carried out in the first person, from a phenomenological logotherapeutic orientation, which emphasizes the experience of self-understanding regarding what specifically constitutes being human and opens the being to existence: awareness of the ability to choose and responsibility towards oneself and their circumstances. The absence of this self-understanding leaves the person at the mercy of nature, learning, society, and destiny. The existential task then consists of achieving that selfknowledge and assuming the leading role in one's life. Existing implies not only being free, but daring to exercise freedom, recognizing in the midst of dissatisfaction and anguish the human condition of being confronted with everything, a fundamental principle of being free. For this purpose, authors such as Viktor E. Frankl, Max Scheler, Martin Heidegger, Karl, Jaspers, Sören Kierkegaard, Rudolf Allers, among others, have been used.
\end{abstract}

Keywords: Freedom, responsibility, person, self-understanding, existence, conditioning, logotherapy, phenomenology, values, Viktor Frankl.

Cualquier uso que se haga de este artículo debe incluir: Autor / Título original de la publicación / ISSN.

\footnotetext{
* Psicólogo: alejandrosalomonp@unife.pe
} 


\section{LA IMPORTANCIA DE SABERSE LIBRE}

Empezaré por hacerme la siguiente pregunta: ¿soy libre? Es decir, ¿somos libres las personas?, ¿o estamos determinadas en nuestro pensar, sentir y actuar de antemano, o empujadas sin remedio desde un espacio oculto de nuestro ser a comportarnos de cierta manera? En la respuesta a esa pregunta radica la forma en la que soy en el mundo. Qué tan satisfactoria o insatisfactoria es mi vida depende en mucho de la respuesta que pueda dar. Para poder responder tengo que situarme en la vivencia ontológica de ser persona. Entonces me surge un acto de conciencia, descubro que estoy haciéndome esa pregunta porque puedo hacérmela. Miro a mis dos gatas recostadas en el mueble y me pregunto si ellas pueden hacer lo mismo que yo. Creo que no, que algo me diferencia de ellas, más allá de la memoria asociativa y la inteligencia práctica que compartimos (Scheler, 1957). Es que ninguna de ellas puede referirse a sí misma, llamarse a sí misma Yo. Y a la vez ninguna de ellas puede llamarme Tú. En ellas, como en todo ente no humano, no existe esa capacidad, ese don que podemos llamar conciencia. Pero esta conciencia tiene una particularidad, porque mis gatas se dan cuenta cuando yo llego a casa, pero no saben que se han dado cuenta, y no saben que aquel de quien se han dado cuenta es un otro.

La conciencia entonces me abre a un entorno distinto al del animal y al de toda otra cosa. Quedo abierto a un mundo, en el que me encuentro contrastado y confrontado con todo aquel y aquello que no soy yo mismo, y con lo que inevitablemente soy relación. Ahora, frente a esta realidad ontológica, al saber que soy yo quien escribe estas líneas, descubro que puedo dejar de hacerlo o que puedo seguir. Yo tengo que elegir, pero básicamente porque puedo. $\mathrm{Y}$ este poder constituye mi libertad. Mis gatas también eligen entre comer galletas o paté, solo que no lo hacen ellas, algo les dice qué elegir. Para ellas no hay opciones, ellas son su instinto (Frankl, 2007). Pero yo, que puedo llamarme yo, soy consciente de que en el momento en el que estoy frente a mis posibilidades soy irremediablemente irremplazable, insustituible. Nadie puede tomar esa decisión por mí, es una respuesta que yo debo dar ante una vida que reconozco como solo mía. Soy tan libre como responsable. Pero entonces, si hay libertad, ¿puedo también ser prisionero o algo así? O dicho de otra forma ¿es la libertad algo que tengo que alcanzar?
En cierto sentido si, y en cierto sentido no. No en el sentido de llegar a ser libre, porque libre ya soy, porque puedo elegir, sino en el sentido de ejercer mi libertad, de conformar mi propia vida, de moldear mi propio carácter (Frankl, 2013). Es decir, basándome en que puedo decidir, decidir-me. Entonces se conjugan tres aspectos que caracterizan a una existencia: la conciencia, la libertad y la responsabilidad. Adueñarme de mi vida implica ejercer mi libertad, asumirla en un sentido positivo, afirmativo. Es un acto de madurez espiritual, un emerger del espíritu (cf. Kierkegaard, 1984), donde no soy solo libre, sino que existo, lo que significa que valiéndome de mi libertad puedo elegir voluntariamente ser quien yo elija. Aquí el papel de la conciencia es principal, pues la libertad en ese sentido activo es tan solo una posibilidad, una facultad que hay que actualizar, para lo cual es imprescindible saber que soy libre y que por serlo puedo decirle que no a cualquier cosa (Scheler, 1957), y esto porque puedo o-ponerme (Frankl, 2007) a cualquier condición y justamente en esa oposición del espíritu despierta lo específicamente humano. Despierto a mi libertad, una libertad que ya me constituye, pero de la cual debo valerme para construir mi existencia. Si en este - y solo en este- sentido no la alcanzo, quedo a merced de todo lo contingente, de todo lo que se me presenta como condicionantes a mi existencia (cf. Frankl, 2007) y que son siempre algo con lo que me puedo enfrentar y ante lo cual siempre estoy adoptando una actitud. Esos aspectos conforman también mi personalidad, intervienen en mi forma de sentir, de pensar, de actuar, de relacionarme, y pueden someterme, adueñarse de mí sin que yo sepa que eso está pasando. Uno de estos aspectos es todo aquello que se relaciona a lo natural que es en mí, pues soy también - aunque no solo naturaleza, a lo que llamaré lo psicofísico, constituido por la interacción entre las dimensiones biológica y psíquica, que conforman así una unidad en la que nada es exclusivamente biológico y nada es exclusivamente psíquico.

Lo instintivo y lo heredado genéticamente se manifiestan psicológicamente como impulsos y reacciones relacionadas a mi temperamento y la satisfacción de necesidades. También pertenece a lo psicofísico todo lo que he ido construyendo en mi mente a manera de aprendizajes condicionados, los significados que atribuyo a los hechos, mis 
interpretaciones acerca de las situaciones, mis creencias, valoraciones, prejuicios, percepciones, convicciones, definiciones y teorías aprendidas a lo largo de los años y que conforman mi carácter y mi identidad. Además, está mi relación con el mundo, con los demás, con los valores familiares, con la sociedad y la cultura, con las tradiciones y la idiosincrasia de mi comunidad. Esto es lo sociológico. Puedo vivir acostumbrado, habituado, sin cuestionarme nunca acerca de cómo todos estos aspectos juegan un papel en mi vida, cómo es la relación que tengo con ellos. ¿Es una relación a ciegas donde estos aspectos determinan mi existencia o es una relación consciente donde sé que puedo elegir libremente una actitud frente a ellos? Vivir sometido es vivir prisionero de los condicionamientos, pero estando en libertad. Porque en realidad me dejo someter (cf. Frank1, 2007), y este dejarme es una decisión propia que nadie más toma. Al final, quiera o no, consciente o inconscientemente, yo elijo siempre quien ser. Mi libertad es algo a lo que, aunque intente, no puedo renunciar.

Sin duda puede ser más fácil o cómodo vivir sometido, pues asumir mi libertad y ejercerla es atreverme a tener el coraje para conquistarme y ser yo mismo. Esto quiere decir que soy yo quien responde a las preguntas que me hace mi vida, consciente de aceptar las consecuencias de mis decisiones como mías. Siendo así yo decido mi propio camino, construyo mi propio proyecto, me permito ser verdadero en mis vínculos. En la obscuridad de la falta de comprensión sobre mi condición humana quedo a expensas de la vida, como un bote sin velas en medio de un mar que lo dirige. Viene a mi mente Sócrates: "conócete a ti mismo". La conciencia de mi libertad es el punto de partida.

Ahora bien, ser libre es algo que comienza solo como un potencial, pues ciertamente cuando yo era un bebé pequeño era muy parecido a mis gatas, en el sentido de estar regido por el instinto y el impulso afectivo. Pero poco a poco me fui descubriendo distinto a todo y a todos, y cada vez más consciente de cual era mi puesto, mi lugar en el cosmos (cf. Scheler, 1957). Mi conciencia me fue abriendo poco a poco al mundo. Mis padres siempre con la cantaleta de "tienes que decidir cuál quieres", "no podemos comprarlos todos, tienes que elegir uno" o "depende de ti, es tu juguete", me fueron anunciando a punta de tensión la buena nueva de mi propia libertad. Hasta aquella vez que tuve completa conciencia de que ellos no me resolverían la vida (¡también fui consciente de que ni siquiera podían resolver la suya!), que yo tenía que ser quien resuelva de ahora en adelante, en especial quien ser. Pero con el tiempo me fui habituando a lo que había aprendido a ser, identificado con ciertas cualidades, acomodado a la expectativa social y cultural, y poco a poco fui perdiendo de vista mi libertad. Esta estaba siempre conmigo, como algo que soy yo mismo, porque no puedo perderla como quien tiene algo (Frankl, 2008), pero fuera de mi autocomprensión, fuera del alcance de mi conciencia, quedando solamente como un atributo durmiente. Pero haberla perdido de vista no significa que ya no sea, pues mientras tenga conciencia de mi existencia puedo elegir frente a mis posibilidades y sigo siendo libre, pero sin saber que del uso que haga de esa libertad depende la actitud con la cual enfrento mis circunstancias y vivo mi vida. Se trata entonces de descubrir lo que ya hay, de esclarecer lo que me constituye como persona, aquello que Frankl (2007) llama lo espiritual, todo lo que hay de libre en mí, desde donde puedo tomar una postura, cualquiera que fuera. Este conocimiento de mí mismo, esta confirmación de mi condición de persona, me permite ejercerme como dueño de mi existencia.

Pero este esclarecimiento pasa por un diálogo conmigo mismo, un autodistanciamiento (Salomón y Díaz del Castillo, 2019) que me permita observarme en situación y poder reconocer lo que siento. Y ¿qué es lo que siento que me puede ayudar a confirmar mi propia libertad? Si esta libertad se relaciona a que puedo elegir frente a mis posibilidades, entonces en la circunstancia de decidir he de estar atento a mi sentir. ¿Qué siento entonces cuando estoy frente a una elección? Mi respuesta es: angustia. Aquella dama oscura y agitada que me asalta cuando me toca decidir. Aquel sentir sobre el cual aprendí que es mejor erradicarlo, porque es un malestar y es el síntoma anímico de algún conflicto interno. Pero lo cierto es que esa angustia no solo es un malestar sino también y sobre todo la señal de que soy libre para elegir y que nadie puede hacerlo por mí, y que al decidirme actualizo una posibilidad perdiendo todas las demás. Saber que de mí depende el momento siguiente me genera un vértigo (Frankl, 2008), porque elegir es un 
salto de fe (Kierkegaard, 1984), un salto al vacío de lo incierto, un salto cualitativo en el que asumo mi protagonismo existencial. Al elegir se me angostan las posibilidades al igual que mi respiración, es una experiencia de angostura. Ya decía Viktor Frankl que solamente un ser que es libre puede sentir angustia (Frankl, 2008). Reconocerla es entonces la puerta de entrada para despertar a ser libre y responsable. Y este reconocimiento pasa por el hecho de que mis actitudes, cualquiera que fuera, son siempre elegidas por mí. Es decir, la disposición con la que me paro frente a mis circunstancias me pertenece, yo la decido. Siendo así me empiezo a cuestionar: ¿cómo es que estoy eligiendo ser de esta forma? ¿Es una elección desde mi libre voluntad o estoy decidiendo desde algún oscuro rincón de mi inconsciente de forma instintiva, o empujado por algún hábito o siguiendo como autómata lo que los demás deciden sin percatarme? Sea como sea, yo estoy decidiendo esa actitud. Yo actúo y en función de lo que hago me construyo. Porque soy yo quien frente a mis posibilidades opto, ya sea para conquistarme a mí mismo o para dejarme llevar o empujar. Estoy en libertad porque podría decidir algo distinto. Con cuánta razón decía Frankl (2007) que incluso al abdicar a mi libertad lo hago libremente. Si no acepto esto jamás podré ejercerla, recordando al gran Karl Jaspers (1958): el hombre es el ser que elige quien ser.

\section{LA OPOSICIÓN DEL ESPÍRITU COMO EJERCICIO DE LA LIBERTAD}

Una vez que he descubierto mi libertad no hay marcha atrás. He abierto la puerta y he visto, y aunque la cierre, no puedo volver a la ingenuidad en la que vivía. He salido de lo empírico para entrar en lo existencial (Jaspers, 1958), me abro al mundo. Ahora sé que tengo un margen de independencia que en la vida natural no he estado ejerciendo. La vida en piloto automático me trae un precio que pagar: el de no ser yo mismo. Y ser yo mismo es saberme parado ante todo lo que me sucede, todo lo contingente que me condiciona. El reto de mi libertad es ejercerla ante aquello de lo que no soy libre, pues no se trata de ser libre de condicionamientos sino libre para decidir qué hago frente a ellos (Frankl, 2013). Y esto pasa por el acto que Max Scheler (1957) llama de humanificación, el poder hacer de las cosas objetos y con esto la posibilidad de decirle no a todo aquello con lo que estoy enfrentado. Esto significa afirmarme frente a mi biología, mi psique y mi medio. Puedo, desde mi libertad, hacerme frente a mí mismo y al mundo. Puedo observarme, controlarme, darme permiso, reconciliarme incluso. Puedo no seguir lo que todos hacen o lo que quieren que haga. O hacerlo porque así lo decido desde mi más propia voluntad. No se trata de siempre ir diciendo que no a todo, sino de saber que puedo, y en ese poder radica mi libertad última (Frankl, 2013), la de elegir, y por tanto decidir sobre la actitud con la que vivo mi vida.

\section{AFIRMARME ANTE LO PSICOFÍSICO}

Lo psicofísico es una dimensión de mi ser. Corresponde a todo lo que hay de natural en mí, que se rige por la naturaleza. Esta es mi dimensión de vida, cuya tendencia es hacia el bienestar, hacia el equilibrio. Toda la carga genética se propaga a través de esta dimensión. Acá se encuentran los procesos vegetativos automáticos y es la base fisiológica de las funciones mentales más simples hasta los actos humanos más elevados que podríamos llamar espirituales (cf. Scheler, 1957), como la vivencia del arte o la acción ética. Como parte de esta dimensión se encuentran también el instinto y el temperamento, como dos condicionantes ante los cuales ejercer mi libertad. Dos aspectos cuyo funcionamiento organísmico y automático pueden someterme si no me afirmo, si no tomo postura ante ellos. El instinto como programación biológica provee de impulsos que tienden a la satisfacción de necesidades del organismo, lo cual puede ocurrir de forma inconsciente, sin que me percate. Pero cada reacción impulsiva es una acción que yo realizo y por la que debo asumir la responsabilidad. No puedo culpar a mi instinto por un grito que doy, o por dejarme llevar por un impulso, como por ejemplo un acto de infidelidad hacia mi pareja, pues todo esto lo realizo en libertad. No soy puro instinto, este no me constituye como al animal (Frankl, 2007), sino que lo tengo, ya que puedo, desde mi libertad, oponerme a aquel. Mi instinto es energía pura en su impulsividad, que debe ser de alguna forma encausada desde mi voluntad hacia una acción con sentido. El instinto proporciona el impulso, pero ya no la conducción, que he de llevar yo mismo. Si no tomo el timón el instinto lo hará en su función de resguardo, de protección o supervivencia, o de satisfacción de alguna necesidad, y decidiré empujado, sin ser consciente de qué hago, 
cómo lo hago ni para qué lo hago. Oponerme al instinto es ser yo quien dirija, consciente de mí mismo respecto a mi papel en mis decisiones. He desactivado el piloto automático biológico. Desde mi libertad hago uso legítimo de mi humanidad, de lo más humano que hay en mí, para autorregularme (cf. Martínez, 2011) pasando mi instintividad por el filtro de mi conciencia y mi voluntad. Entonces dejo de ser uno más de la especie para convertirme en yo mismo.

Afirmarme frente a mis instintos es ejercer mi libertad, es emerger al mundo de la existencia, donde predomina la conciencia del elegir. Ya no es más una motivación pulsional lo que me mueve, un sentirme empujado a ser de cierta forma. Ahora las motivaciones son mías. Si ya nada me empuja desde "adentro", quedo en la disposición para ver lo que hay afuera: un mundo lleno de valores y sentido (Frankl, 2004). Mi instinto ya no me dirige, sino que me brinda la energía para dirigirme hacia donde yo decido ir. En este ejercicio de mi libertad no prima la voluntad de placer (Frankl, 2013), esa tendencia hacia el alivio y la distensión, sino que más bien predomina la voluntad de sentido (Frankl, 2013), validando la angustia propia de decidirme por lo verdaderamente importante para mí. Se genera así una tensión entre quien vengo siendo y quien llegar a ser, entre mi ser actual y mis posibilidades, en las que capto valores. Elijo asumir el control de mi impulsividad, intuyendo los valores posibles, como ya no golpear las cosas en un arranque de frustración porque percibo afectivamente que controlarme es importante. Aparece en mi mente el rostro de mi pequeña hija como aquel valor que me mueve a oponerme a esa instintividad. Se trata del salto de Kierkegaard, un salto cualitativo donde en mi elección me conquisto a mí mismo, adueñándome de mis decisiones y acciones. En algunas miradas de la psicología podemos encontrar que esta idea es completamente ilusa, ya que no habría forma de escapar del dominio del inconsciente, con lo cual se reducen los fenómenos humanos a procesos psíquicos relacionados a represiones y pulsiones instintivas. Desde la perspectiva de la logoterapia y el análisis existencial como persona estoy en posibilidad de elevarme por encima de mis instintos. Doy por hecho que soy libre, me lo indica mi autocomprensión ontológica pre reflexiva (Frankl, 2003), es algo que pertenece a los datos inmediatos de mi experiencia
(Frankl, 2003), pero que puedo olvidar al sumergirme en una actitud natural, en la que vivo sometido y definido por mi instinto. Pero no soy mi instinto. Yo soy quien se para frente a aquel, para decirle que sí o que no. Tengo una relación con mi instinto.

Por su parte, el temperamento es aquello que he heredado genéticamente y se relaciona a mis predisposiciones anímicas y mis expresiones afectivas espontáneas con el entorno. Es mi dimensión biológico - anímica, mi manera natural de relacionarme con el medio, carente de intencionalidad afectiva, pues pertenece a lo psicofísico que es en sí mismo cerrado. Yo no elegí este temperamento colérico que heredé de mi padre, pero hay algo que desde mi libertad puedo hacer, y es elegir qué hago con eso, cómo me relaciono con aquel temperamento. Este poder se fundamenta en que soy relación con todo y no un ser que se encuentra extático (Scheler, 1957), fundido en una unidad impersonal con la naturaleza, por lo que tengo la capacidad de adoptar una actitud ante cualquier cosa. Es más, no solo puedo, sino que siempre - salvo al dormir y en estados de pérdida de la conciencia - estoy disponiéndome al mundo de alguna manera. Pero si no soy consciente de esta cualidad ontológica pierdo de vista aquello que me hace ser precisamente humano, ser persona, ser una existencia propia abierta al mundo. He estado trabajando mi impulsividad e ira en terapia, revisando fenomenológicamente mi experiencia, ampliando mi comprensión sobre qué hago, cómo lo hago y para qué lo hago, analizando existencialmente mis relaciones con el mundo, con los demás, conmigo mismo y con mi propia historia. Ahí en ese conocimiento de mí mismo es que aclaro mi existencia lo suficiente como para notar mi condición humana, sabiendo que esta impulsividad no me define, no es yo mismo, yo todo, sino algo que poseo como un aspecto de mi personalidad. Este distanciamiento me permite notar la relación que tengo con este temperamento que no he elegido tener, pudiendo distinguir si es que mi actitud para con él es más un sí pasivo e involuntario o un no personal y auténtico. Si soy como mis padres o mis abuelos depende de mí, en definitiva. No puedo culpar a mi herencia por mis acciones, pues si le digo que sí a mi temperamento lo hago pudiendo decirle también que no. Lo hago en situación de libertad, pues como ser libre me corresponde moldearme a mí mismo y esto es ser responsable. "Grito porque es algo 
de familia”, es lo más neurótico que puedo exclamar, si es que no despierto a lo espiritual que es en mí, si no doy ese salto cualitativo para apelar a mí mismo en un acto de confianza propia y profunda, y ejercerme ante mi impulso. Pero como hemos visto, no siempre tiene sentido decir que no, por lo que mi temperamento, conducido por mí mismo desde mi voluntad y conciencia, es pieza clave en mi estilo de personalidad, para que cual energía biológica me brinde el sustento para mi forma de ser en el mundo. Esto implica decirle que sí hasta cierto punto o de cierta forma, un sí consciente y propio, intencional. La necesidad de recobrar mi autocomprensión prerreflexiva sobre mi propia libertad y responsabilidad es el requisito indispensable para así adueñarme de mí. Si no es así quedaré sometido por lo biológico y hereditario, viviendo una vida natural sin desplegar mi libertad, sin ejercerla como protagonista de mi existencia.

Lo psíquico es una dimensión ligada aun a la naturaleza. Su funcionamiento es hasta cierto punto automático, presente como un fondo desde el cual se manifiestan las conductas de manera espontánea. Lo psíquico cumple junto a lo biológico, un papel de cuidado, en este caso cuidando de mi estabilidad emocional y mi identidad construida (Martínez, 2011). Lo psíquico se cierra en la medida en que sus contenidos y su funcionamiento natural tienden a lo estable y seguro. De ahí que mi mente esté llena de aprendizajes, prejuicios, significados, valoraciones, teorías, interpretaciones y toda forma de conocimiento cerrado, definido, que me brinda un suelo estable, una identidad segura. Vivir desde lo psíquico implica dejarme llevar por mi carácter, por mis aprendizajes y hábitos, sin cuestionar mis creencias ni mis formas de interpretar los hechos. Implica estar convencido de que así soy, sin siquiera mirarme a mí mismo un momento, sin dialogar con mi propio ser. Y este ser así siempre va seguido de alguna característica. Soy impulsivo, soy nostálgico, soy renegón, etc., donde nunca termino hablando de mí sino de aquellas características de mi personalidad con las que me identifico. Esta identificación me confiere una identidad que de ninguna manera soy yo mismo. De acuerdo a mi condición ontológica de persona puedo tomar distancia de mi carácter, para moldearlo (Frankl, 2007), porque puedo, porque está en mis posibilidades asumir una actitud afirmativa de mi ser frente a mi propio psiquismo. Pero si no realizo esta afirmación, entonces mi personalidad toma posesión de mí, y es cuando me asalta la sensación horrenda y desesperante de que no puedo ser distinto, lo cual se constituye como una convicción incluso a nivel inconsciente. Pero este horror es por un lado, pues por el otro el saber que no puedo ser una versión distinta me trae una gran calma, una tranquilidad, pero que se mezcla con la insatisfacción de una vida que no siento auténtica. Solo puedo ser auténtico en el gobierno de mí mismo y al asumir la angustia propia de ejercer mi libertad, para decirle que sí o que no a mi personalidad, o-ponerme conscientemente a todo aquel funcionamiento mental que intente sujetarme a lo ya establecido, a lo ya construido, para convertirme en piedra.

Puedo ejercerme frente a mis creencias, cuestionándolas, o decidiendo ser distinto a cómo he aprendido a ser. Por esa capacidad de elegir que tengo como persona es que recae en mi la responsabilidad de elegirquien ser(Jaspers, 1958), pues, asícomo me puedo dejar llevar libremente por mis condicionamientos y aprendizajes, también puedo ponerme freno, decirme "no más", e incluso mirar mi historia con valor, para enfrentarme a mis vivencias con la posibilidad de hallarles sentido. Puedo reconciliarme conmigo mismo, abrazarme desde mis cuarenta y tres años hacia el de dieciséis, experimentándome en ambos, en un diálogo. Porque puedo dialogar conmigo y con los demás, en la conciencia de que soy distinto y único, siempre un otro, y eso es algo que pertenece a mi condición humana. No hay otro ser que pueda confrontarse con cualquier cosa, y es en esta confrontación cuando nazco a mi libertad, cuando realizo el acto de volverme humano. Yo no soy mi personalidad, no soy mis creencias, no soy mis prejuicios, no soy mis percepciones, ni mis definiciones. Soy aquel que puede enfrentarse a todo ello asumiendo una postura. Saberlo y hacerlo voluntaria y personalmente es ejercer mi libertad. No saberlo me conduce a ser esclavo de mi carácter, como aquella dimensión de mi personalidad que se asocia a lo aprendido, es decir, como he aprendido a ser. Pero mi personalidad no solo es lo heredado y lo aprendido sino también lo elegido (Acevedo, 2010), cómo decido enfrentar los condicionantes, tanto lo biológico (instinto y temperamento) como lo psíquico (carácter) que me constituyen. Lo elegido es mi aporte personal ante lo natural que es en mí. En 
este sentido, la autorregulación (Salomón y Díaz del Castillo, 2019) es mi capacidad para tomar las riendas, actualizando la posibilidad de usar el poder de oposición del espíritu (Frankl, 2007) y arriesgarme a decirle no a los mandatos de lo psícofísico (Martínez, 2011), a decidirme por ser distinto a como me he definido a lo largo del tiempo. Este atrevimiento trae consigo una transformación de mi identidad, pues dejo de ser el que "soy" para abrirme a quien puedo llegar a ser. Esta decisión riesgosa es motivada ya no desde un empuje o impulso psíquico - instintivo, sino que la motivación proviene del mundo, y son los valores los que me atraen, todo lo importante que puedo intuir afectivamente en mis posibilidades de ser distinto. Entonces, si mi organismo psicofísico tiende a cerrarse para la preservación anímica y de identidad, desde lo espiritual tiendo más bien a la apertura al mundo, permitiéndome percibir y realizar lo valioso. Ejercer mi libertad frente a mi mente es dar un giro existencial: de la absoluta inmanencia a la trascendencia. Me autotrasciendo cuando voy más allá de los límites de mi psique, cuando me aventuro a dar el salto que implica ser una versión distinta de mí mismo y con esto abrirme al mundo. En esta apertura y este emerger genuino es que alcanzo a vincularme realmente con los demás siendo yo mismo y contemplando a los demás en su valor esencial personal, pues ya no representan tan solo amenazas a mi seguridad emocional o medios para algún fin regulador. Mientras no sea consciente y no me autocomprenda respecto a mi ser libre, estaré viviendo de modo natural, definido por mí mismo sin percatarme, reducido a lo que ya conozco de mí, a quien estoy convencido que soy, una identidad que se ha hecho rígida.

Mucho de esta experiencia de inautenticidad pasa por estar sumergido en el lenguaje. Esto significa que no me distingo de él, sino que soy mi lenguaje mismo, sin percatarme de sus implicancias en mi vida, en la forma como me represento el mundo, en como percibo las cosas, en las interpretaciones que hago de los hechos. El lenguaje es la manifestación simbólica de la realidad que experimento, es el sustento de mi comunicación con los demás. Refuerza constantemente todos mis esquemas, mis creencias, mis valores, mis miedos, mis prejuicios y mi identidad misma. No tengo forma de ser en el mundo si no es a través del lenguaje (cf. Heidegger, 2014), estoy inmerso en él y él en mí. Pero esto no significa que no tenga la posibilidad de observarlo, de hacer del lenguaje un objeto para mi conciencia. Este distanciamiento no significa ser independiente del lenguaje, pues como hemos visto sin lenguaje no es posible la existencia, pero sí ser independiente frente a él, lo cual implica que puedo elegir la forma en la que lo construyo y utilizo. Las palabras y las relaciones entre ellas no solo me sirven para comunicarme con los demás sino conmigo mismo, representándome la realidad de tal forma que puedo llegar a creer con convencimiento absoluto - y en especial inconsciente - que soy aquello que digo que soy, que mis palabras expresan la realidad misma. El lenguaje tiene un componente aprendido, no solo en su forma de herramienta de expresión sino en los significados que lo constituyen. Las cosas me han sido dadas ya masticadas y las he incorporado en forma de palabras y conceptos, porque llegué a un mundo lleno de valores culturales y tradiciones de todo tipo ya establecidas. Pero no es algo común ponerme a pensar en eso, ni en el hecho de que inevitablemente, al ser una existencia en el mundo, soy relación con todo, incluyendo por supuesto al lenguaje mismo.

Como ya hemos visto, en este enfrentamiento radica el estar abierto a mis posibilidades, y con esto ser libre de elegir entre ellas para actualizar una. Puedo entonces descubrirme en libertad para actuar con libertad, comprendiendo la forma en la que configuro mi realidad a través del lenguaje en relación conmigo mismo y los demás, para así decidir moldearlo, cambiarlo, configurarlo, abierto a que las palabras puedan significar otras cosas y a que surjan nuevas palabras, dispuesto a que mi realidad cambie y asumir la angustia de semejante decisión. Puedo entonces pasar de un pasivo y quejumbroso "así soy" a un más consciente "tengo momentos en los que..." y con esto asumirme como temporalidad, dinámico, sin definiciones, abierto a mis posibilidades. Esta experiencia es la de un lenguaje más propio. Me he hecho dueño de mis palabras y su sentido. Modificar mi lenguaje es modificar mi identidad y mi ser con las demás personas. Puede significar romper las cadenas que me mantienen en la caverna. Recobrar la autocomprensión de mi propia libertad es el primer paso para esta conquista semántica. 


\section{AFIRMARME ANTE LO SOCIOLÓGICO}

Una característica de mi existencia es la relacionalidad con el mundo en el que soy con los demás y lo demás. Este mundo trae consigo todo aquello que, por haber yo nacido en un determinado tiempo y lugar, con tales o cuales personas, constituye la cultura dominante. Son las tradiciones, las maneras de pensar, la idiosincrasia del grupo humano que conforma el mundo que conozco y en el que convivo. La herencia no es solo psicofísica sino también social y cultural, y todo lo que en algún momento aprehendí en mi relación con el mundo pasó a ser parte de mi psiquismo y mi personalidad. Desde pequeño las experiencias fueron moldeando mi carácter, el mundo en forma de relaciones y vivencias configuró de a pocos mi identidad y personalidad. Mis padres $\mathrm{y}$ otros adultos consciente o inconscientemente me impusieron una concepción razonable. Así en lugar de una apertura al descubrimiento espontáneo fue apareciendo un aleccionamiento pasivo y $\mathrm{mi}$ curiosidad se fue truncando (cf. Allers, 2019). Es al ir madurando psicofísicamente cuando me pude distinguir y confrontarme conscientemente con todo esto aprendido. Por eso tengo la posibilidad de decirle que sí o que no a esta cultura en la que estoy inmerso, habituado, normalizado, para así de forma voluntaria asumir una actitud ante todo aquello que se me presenta, poseedor de un filtro de conciencia que me permite masticarlo todo y no tan solo tragarlo.

La ausencia de autocomprensión me deja a merced de lo social, que tan solo me condiciona, pero que en la experiencia de incomprensión ontológica de mi libertad experimento como una determinación. Es entonces cuando caigo ciegamente en el conformismo (Frankl, 2008) que es hacer lo que los demás hacen, no siendo en el mundo como una existencia propia sino fundido con la cultura como un uno más en la masa, en la colectividad, seguidor de lo establecido y enajenando mi responsabilidad al entregarle las riendas de mi vida a la tradición y a la idiosincrasia imperante. Soy entonces lo que el mundo hace de mí, sin que yo tenga ese protagonismo al que estoy llamado, ese puesto que implica la comprensión de estar confrontado siempre con el mundo y por ende ante la posibilidad de decidirme por alguna posibilidad: dejarme llevar o decir que no. Porque ser libre es tener posibilidades. Mi responsabilidad radica en que nadie salvo yo puede elegir por mí entre ellas. Pero hay algo peor aún, pues puedo caer en el totalitarismo (Frankl, 2008), que es hacer lo que los demás quieren que haga, sin que mi libre voluntad sea ejercida. Un dogma, una orientación política o filosófica, representada quizá por algún jefe o líder guía, es el fondo en el cual perderme, huyendo de mi propia responsabilidad. Es más fácil no ser yo mismo, aunque la angustia esté enquistada hasta volvérseme desesperación. Echarle la culpa al pastor, después de haber decidido hacer lo que dijo que había que decidir hacer y haberme equivocado, no tiene sentido, porque la libertad no es algo ajeno a mí y que deba conseguir, sino una posibilidad inherente a mi ser persona que puedo actualizar en un ejercicio auténtico y que en su forma más básica constituye el fondo de todas mis acciones y actitudes, que son elegidas por mí, como haber decidido hacer lo que otro quiso que haga para aliviarme la responsabilidad de decidir qué hacer con mi vida. Pensar en esa responsabilidad, en ese ejercicio de mi libertad, me hace sentir un escalofrío (Frankl, 2013), y ese vértigo frente al abismo insondable de mi elección y de mis posibilidades. Me mareo al pensar que de mí depende si vivo una vida social o una existencia (cf. Jaspers, 1958), si vivo sometido por los convencionalismos, por los dogmas, por las ideologías y por lo que la masa espera de mí como un agente más en esa maquinaria impersonal donde mi individualidad queda diluida en lo colectivo, o si despierto al ejercicio de mi libre voluntad, que es el verdadero despertar de mi espíritu, el emerger al mundo de la existencia como protagonista de mi propia trama.

Solo desde mi propia posibilidad es que puedo realmente estar abierto al mundo (Scheler, 2001), resonando afectivamente y saliendo al encuentro de los demás y de las cosas, realizando esos valores vivenciales (Frankl, 2013) que contribuyen a que mi vida tenga sentido, desde las experiencias genuinas del amor y la sincera amistad hasta la contemplación de un bello atardecer. La vida empírica y social es, por más paradójico que suene, cerrada al mundo, incapacitada para lo trascendente, por lo que mis relaciones con las demás personas se hunden en lo impersonal y superfluo, sin que me vincule, ya que es necesario que sea yo mismo para poder encontrar a un otro en la legitimidad del verdadero encuentro, donde tanto yo como el otro somos insustituibles en la comunicación. Siendo un 
uno más en lo colectivo no me poseo lo suficiente como para ser una individualidad que se autotrasciende (Frankl, 2007) hacia el mundo, y este poseerme pasa por realizar la premisa socrática de conocerme a mí mismo, sobre todo respecto a mi libre voluntad, a que puedo elegir entre mis posibilidades y por ende soy libre y además responsable de mí mismo, de lo que hago de mí. El mundo me configura y yo configuro al mundo, pero en esta dinámica estoy siempre, por ser persona, confrontado con él. El mundo está frente a mí, y mientras me envuelve, se me presenta siempre como lo otro, como el no - yo (Allers, 2019). Precisamente mi libertad se relaciona a esa cualidad de mi ser de estar siempre confrontado (Frankl, 2007). Al final si lo social me conquista será mi decisión, será mi dejarme conquistar, mi libre abdicación a mi libertad. Mi falta de autocomprensión no me exime de responsabilidad.

\section{AFIRMARME ANTE EL DESTINO}

¿Qué es el destino? No lo veremos como algo preestablecido, como si ya estuviera predestinado a vivir ciertas experiencias. El futuro es incierto, es la nada, el proyecto, las posibilidades. El destino más bien es lo que me toca vivir (Frankl, 2013) cuando me toca vivirlo. Es mi circunstancia cuando se me presenta, caracterizada por el límite, es decir, por ser una circunstancia que no puedo cambiar. Mi destino es algo de lo que no soy responsable, porque no lo elijo, tan solo llega y me golpea (Lukas, 2004). Frente a este destino ineludible ¿qué podría hacer si no puedo realmente modificar lo que sucede? Viene a mi mente Heidegger (2014), con eso de maravillarme ante lo que es, porque es. Pero, ¿qué tanto esa aceptación de mi situación me determina a resignarme cual estoico ante mi destino? ¿No es acaso una cosa la resignación y otra la aceptación? Porque en la resignación tengo la convicción de que no puedo ya hacer nada, lo cual hasta cierto punto es verdad, pero solo hasta cierto punto, pues en la aceptación quedo abierto a asumir mi condición de confrontado con un destino ineludible e inmodificable, y desde esta posición asumir mi protagonismo, validando ese margen de independencia que poseo, esa libertad que soy ante mis posibilidades. Así que, si bien no puedo elegir cambiar mi destino, sí puedo elegir la actitud con la cual lo enfrento (Frankl, 2007). Es el despertar espiritual que me abre al ejercicio de mi libertad. Si me dejo libremente someter por el destino, dejaré todo en manos de Dios, o del tiempo, o de la vida, dejando mi libertad intacta, sin actualizarla como la posibilidad que siempre es en su ejercicio, sin hacerme consciente de la gran y esencial diferencia entre mis gatas y yo. Esta se constituye en que no hay nada frente a lo cual no esté siempre confrontado y por lo tanto en situación de libertad para decidirme entre mis posibilidades. Y no hay nada más inauténtico que soltar las riendas para dárselas a algo o alguien más. "Que sea lo que Dios quiera", o "ya el tiempo dirá" son expresiones que revelan la no apropiación de mi dignidad, de lo más sublime y humano que me puede constituir y es el poder ser dueño de mí mismo (Martínez, 2019), pues como persona soy el único ser que puede hacer algo semejante. Saberme en calidad de responsable, porque soy yo quien tiene que elegir, es algo difícil de sostener. Ejercer mi libertad pasa por abrazar mi angustia, aprender a sentirla, consciente de que soy inevitablemente yo quien ha de decidir la actitud con la que vivo mi experiencia. Solo de esta forma puedo convertir una situación adversa en un triunfo del espíritu.

\section{LAAUTENTICIDAD COMO EJERCICIO DE LA LIBERTAD}

Toda afirmación que realice frente a lo biológico, lo psíquico, lo social o el destino inmodificable es un acto de autodeterminación, una toma de postura asumida desde la comprensión ontológica de mi propia libertad. Esos condicionamientos constituyen aspectos de los que no puedo prescindir para existir. Soy también en virtud de mi instinto, de mi temperamento, de mis aprendizajes y de mi medio ambiente (Frankl, 2007), están integrados a mí y yo a ellos, no puedo ser sin ellos. La cuestión es qué tanto soy consciente de que entre estos aspectos y yo hay una relación y no una fundición. Vivenciar comprehensivamente esta relación, adueñándome de la responsabilidad de ser yo quien elige la actitud con la cual me dispongo ante mis condiciones, es ser auténtico. Soy auténtico entonces cuando soy yo mismo, cuando respondo por mí ante mis circunstancias, como una individualidad que se sabe única, irremplazable respecto a mis decisiones, insustituible en el drama de mi propia existencia. Esto significa apropiarme de mi ser (Heidegger, 2014), dispuesto a vivir en primera persona (cf. Kierkegaard, 1984), protagonista de mis decisiones y autor de mis 
actitudes y acciones. Enfrentado constantemente con todo me ubico en mi puesto, como un ser incondicionado (Frankl, 2000), libre para elegir mi postura ante mis circunstancias, ya sean internas o externas, asumiendo las consecuencias de cada una de mis decisiones.

En la inautenticidad en cambio me someto a mi instinto, dejándome empujar y naturalizando mis elecciones, aludiendo a que a fin de cuentas "soy un ser de instintos". Lo mismo con mi temperamento, me defino colérico como mi padre y mi abuelo. Mis decisiones se basan en los impulsos de mis predisposiciones anímicas genéticas. Me justifico en mi herencia y así no me abro a la existencia, permanezco en lo impropio, en lo impersonal, en lo cotidiano. "No puedo ser distinto" es la frase característica y es justamente lo que más caracteriza a la neurosis (cf. Frankl, 2008), el haber cambiado la percepción de mí mismo: de ser siempre posible a verme determinado. Y esta actitud conlleva a un huir de mi propia responsabilidad, al no asumirme como capaz de decidir quién y cómo ser. En la inautenticidad mis experiencias me han hecho ser quien soy, producto de lo que he vivido, y creo que soy aquel que he aprendido a ser.

Mi identidad me posee, "soy así porque pasé por esto", o "porque nací y crecí en un ambiente muy negativo", porque he renunciado a ser quien elige quien ser. Pero es una tarea imposible, porque esa renuncia es en sí misma una elección. No puedo perder mi libertad como quien pierde algo (Frankl, 2007), porque mi libertad soy yo mismo. Perder de vista esa libertad es perder de vista mi propio ser. Es un saber que me está velado y al mismo tiempo evito, en esa mezcla de hábito y ansiedad, de estar acostumbrado a ser así, pero sintiendo una insatisfacción de fondo, aquella que me trae la existencia inauténtica. En tal estado de inautenticidad el mundo me conquista, sin que yo aparezca en escena para ser protagonista. Soy lo que el mundo hace de mí pasivamente, siguiendo los pasos de otros por sentirlos más seguros, caminando junto con la masa y las modas para no tener que construir un proyecto propio, lejano de los demás sin experimentar verdaderos encuentros, porque no soy yo mismo, y es imposible co-construir una comunidad con otros sin abrirme al mundo, sin ser co-partícipe de mi existencia como un ser que aprehende la cultura y que la transforma, activo en el sentido de saberse dueño de su vida, en constante relación con todo lo social, y en la posibilidad siempre de elegir la actitud con la cual sostengo esa relación. En la inautenticidad me experimento "como un autómata de reflejos, como una máquina de pensar o un conjunto de instintos, como un peón de impulsos y reacciones, como un mero producto del instinto, de la herencia y del entorno" (Frankl, 2019 p. 152). No se trata de que la inautenticidad sea algo malo, no es ni bueno ni malo. Quizá sí sea algo muy insatisfactorio, dependiendo de qué tan inauténticamente vivo mi vida, qué tanto a través de mis formas de ser me pierdo de una existencia con más sentido, en la medida en que no ejerzo mi libertad ni mi responsabilidad. Pero tanto la autenticidad como la inautenticidad no pueden ser valoradas como buenas o malas, o que una es mejor que la otra (Martínez, 2013), ya que son formas de existir inherentes a mi condición humana.

Si puedo ejercer mi libertad es porque puedo dejar de hacerlo. Mi libertad no es algo absoluto o perfecto, sino una capacidad que me arroja a un mundo en el que me corresponde ocupar mi lugar, y esto significa asumir mi posición como un ser confrontado, siempre en relación y en posibilidad de decidir mi actitud, mi disposición ante las cosas. Ser libre es, siempre que tenga conciencia, ser capaz de elegir entre mis posibilidades, siendo yo mismo mi propia posibilidad (cf. Jaspers, 2006). Y aunque no decida consciente de mi papel, dueño de mí mismo, igual decido libremente, en libertad, y es por eso que soy profundamente responsable. Pero ejercer mi libertad es decidir con libertad, sabiendo cual es mi papel frente a mis circunstancias. Dar el salto de la inautenticidad a la autenticidad pasa por una decisión existencial, donde me asumo, me abro a abrazarme en mis posibilidades y en mi angustia. Ahora bien, ¿qué es lo que me despierta a la existencia auténtica? Lo inauténtico, es decir, la insatisfacción que siento por no ser yo mismo, como una desesperación (Kierkegaard, 2013) por querer ser yo mismo y al mismo tiempo por no querer serlo. Pero esta insatisfacción bien puede ser el acicate para dar ese salto hacia la vida propia, dependiendo de, como siempre, mi actitud ante mis posibilidades. 


\section{LA INSATISFACCIÓN DE LA VIDA INAUTÉNTICA COMO EJERCER LA LIBERTAD INVITACIÓN A}

Vivir mi vida de manera inauténtica me trae una insatisfacción existencial, un conformismo incómodo propio de quien decide soltar las riendas de su vida. Vivir sin asumir que puedo decidir y que este poder me hace libre, es vivir con un petrificado "no puedo" con el que me ubico como un ser natural, psicológico y social, que no puede ser de otro modo, de un modo que yo elija. Puedo describir esta insatisfacción como un "sentirme atrapado", "no sentirme yo mismo", "no sentirme libre", "no comprender por qué soy asî", etc. Vivir así me trae también un alivio sobre la angustia propia de tener que construir mi propio proyecto, por la inevitable apelación a mi responsabilidad que esto representa. Pero, aunque alivie la angustia momentáneamente siento igual esa sensación molesta donde intuyo que todo podría ser distinto, pero distante, difícil de alcanzar. Son los valores depositados en las posibilidades los que me llevan a sentir la insatisfacción, al no estarlos realizando, cuando desde mi conciencia como un órgano de sentido me señalo la posibilidad que tiene más sentido de ser elegida, contemplando al mismo tiempo mi situación vital concreta, apuntando hacia donde he de dirigirme (cf. Noblejas, 2018). Pero dejo de lado ese llamado por lo complicado que me resulta asumir mi protagonismo y decidirme por lo auténtico. Pero no hay forma de evadir mi libertad, pues no puedo culpar ni a mis instintos, ni a mi temperamento, ni a mis experiencias ni a los demás por no realizar los valores. Soy yo el irremediable responsable, aunque coaccionado, aunque en mucho inconsciente, sigo siendo yo quien elige no realizarlos. Los valores me atraen, pero no me empujan (Frankl, 2013), depende de mí el momento siguiente, si me decido por lo uno o por lo otro, y cuando me decido por no realizar lo valioso y quedarme en lo inauténtico aparece la culpa para hacerme saber que soy yo quien debe poner la cara ante mis consecuencias. La conciencia de mi ser libre pasa entonces por reconocer mi insatisfacción como una invitación molestosa a dejar toda forma de ser inauténtica y apostar por el abismo de lo auténtico, que me angustia por ser desconocido, pero está rebosante de valores y sentido. En lugar de intentar acabar con mi insatisfacción distrayéndome en placeres o buscando poder, puedo elegir sostenerla, sentirla y asumirla, escuchar su llamado. Mi libertad tiene pues un fundamento fenomenológico y axiológico. Esa experiencia en la que intuyo que puedo existir de una forma distinta, quizá como una mejor versión de mí, es el componente axiológico de la insatisfacción, donde un mundo de valores me reclama para su realización (cf. Miramontes y Salomón, 2017), y que en la inautenticidad no puedo vivenciar, por estar cerrado, o también en-cerrado, sometido, dominado y determinado desde lo natural, lo psicofísico y lo social. El mundo que fundamentalmente me es algo abierto o ante el cual me abro se me cierra en la medida en que me acomodo a la rutina diaria y lo convencional (cf. Allers, 2019). La insatisfacción es la señal (como lo es la angustia en cada elección), tan solo eso, pues yo soy quien se decide a favor o en contra, soy quien dirá qué hacer frente a esta molestia que es tan solo mía. Ahí están siempre mis posibilidades. Lo que haga con eso, depende mí. La comprensión de mi insatisfacción es el inicio del despertar espiritual, es decir, la autocomprensión de mi ser libre y responsable.

Todo se puede desencadenar a partir de una toma de conciencia, de un acto de autodistanciamiento, donde la chispa del sentido surge en forma de pregunta, de cuestionamiento, como una interpelación desde lo más ético de mi ser: ¿Qué estoy haciendo con mi vida?, ¿qué es esta insatisfacción que siento?, ¿cuál es mi papel en todo esto?, recobrando un originario pero latente saber sobre mí mismo, que aparece cual fenómeno en mi mente gracias a cuestionarme con el verbo hacer, porque algo hago, algo siempre hago, y de esa responsabilidad no puedo desentenderme. También por supuesto puedo despertar gracias a la maravillosa palabra de alguien muy valioso a quien decido escuchar, y su punto de vista me puede ayudar a mirarme desde un lado diferente y cuestionarme.

Es la ineludible conciencia de mi humanidad y lo que eso conlleva. He ahí el despertar que surge al asumir el malestar como aliciente para mirarme a mí mismo con honestidad, consciente de que mi vida espera algo más de mí que solo automatismos y definiciones. Existir implica asumir lo que Viktor Frankl llama el único gran compromiso que representa mi vida (Frankl, 2016). Es un matrimonio con mi propia existencia. Pero, en ese sagrado altar soy yo quien decide si dice sí o no. 


\section{REFERENCIAS}

Acevedo, G. (2010) El modo humano de enfermar. Casa Viktor Frankl

Allers, R. (2019) Mundos anómalos. Un ensayo de fenomenología psiquiátrica. Universidad Católica San Pablo

Frankl, V. (2019) El concepto de hombre en psicoterapia. Nous. Boletín de Logoterapia y Análisis Existencial.2(23) 139 - 153 http://www. logoterapia.net/uploads/23_frankl_2019_hombre. pdf

Frankl, V. (2016) A pesar de todo, decir sí a la vida. Plataforma Editorial

Frankl, V. (2013) Psicoanálisis y existencialismo. FCE

Frankl, V. (2008) Teoría y terapia de las neurosis. Herder

Frankl, V. (2007) Logoterapia y análisis existencial. Herder

Frankl, V. (2004) El hombre en busca de sentido. Herder

Frankl, V. (2003) Psicoterapia y existencialismo. Herder

Frankl, V. (2000) El hombre doliente. Herder

Heidegger, M. (2014) El ser y el tiempo. FCE

Jaspers, K. (2006) La Filosofía. FCE

Jaspers, K. (1958) Filosofía. Tomo I. Ediciones de la Universidad de Puerto Rico
Kierkegaard, S. (2013) Tratado de la desesperación. Grupo Tomo

Kierkegaard, S. (1984) El concepto de la angustia. Orbis

Lukas, E. (2004) Logoterapia. La búsqueda de sentido. Paidós

Martínez, E. (2019) Hazte dueño de ti. Una guía para vivir con propósito y autenticidad. Meaning Corp.

Martínez, .Y (2013) Filosofía existencial para terapeutas y uno que otro curioso. LAG

Martínez, E. (2011) Los modos de ser inauténticos. Manual Moderno

Miramontes, F. y Salomón, A. (2017) Viktor Frankl y Max Scheler. Un ensayo a dos voces (o dos ensayos a un solo espíritu). Revista Mexicana de Logoterapia. 2(8). 13 - 36

Noblejas, M. (2018) Afinar la conciencia, responder a la vida. Realizando sentidos, formando la conciencia. Nous. Boletín de Logoterapia y Análisis Existencial. 2(22) 21 - 37 http://www. logoterapia.net/uploads/22_noblejas_2018_ responder.pdf

Salomón, A y Díaz del Castillo, J (2019) Encontrando y realizando sentido. Diálogo socrático y ejercicios vivenciales en logoterapia. LAG

Scheler, Max (1957) El puesto del hombre en el cosmos. Losada

Scheler, Max (2001) Ética. Caparrós

Fecha de recepción: 29 de abril 2021

Fecha de aceptación: 3 de junio 2021 